\title{
VARIATION IN COVID-19 INFECTION PARAMETERS ENDORSE THE CALL FOR GREATER EFFORTS IN PERSONALISED MEDICINE
}

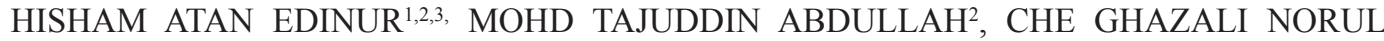 \\ HAJAR $^{1}$ AND GEOFFREY KEITH CHAMBERS ${ }^{4}$
}

${ }^{1}$ School of Health Sciences, Universiti Sains Malaysia, Health Campus, 16150 Kubang Kerian, Kelantan, Malaysia. ${ }^{2}$ Institute of Tropical Biodiversity and Sustainable Development, Universiti Malaysia Terengganu, 21030 Kuala Nerus, Terengganu, Malaysia. ${ }^{3}$ Environmental Futures Research Institute, Griffith University, Nathan, Queensland 4111, Australia. ${ }^{4}$ School of Biological Sciences, Victoria University of Wellington, P.O. Box 600, Wellington, New Zealand.

*Corresponding author: edinur@usm.my

Submitted final draft: 31 January 2021 Accepted: 1 April 2021

http://doi.org/10.46754/jssm.2021.08.003

\begin{abstract}
New data on several COVID-19 infection parameters are slowly beginning to emerge which include the relative frequencies of symptomatic versus asymptomatic individuals positive for COVID-19, individual variation in response to re-purposed drug treatments, prognostic factors for developing severe COVID-19 and genetic risk factors for COVID-19 susceptibility and severity. From a larger perspective, it is our view that these parameters endorse the call for greater efforts in personalised medicine, especially when specific pharmacological interventions (i.e. vaccines or drugs to COVID-19 and other zoonotic diseases) are yet to be developed. Here, the aim of personalised medicine would be to rapidly identify vulnerable individuals and subsequently to design better treatment regimens for them, should COVID-19 or other pandemics appear in future. Application of genomic technology also will continue to be of importance to gain knowledge about the biology of the virus and will facilitate vaccine development and predict markers of resistance and/or susceptibility.
\end{abstract}

Keywords: COVID-19, personalised medicine, susceptibility markers, genetic variants

Abbreviations: Coronavirus disease 19 (COVID-19), severe acute respiratory syndrome coronavirus (SARS-CoV-2).

\section{Introduction}

As of June 2020, most parts of the world have now been affected by an outbreak of coronavirus disease (the COVID-19 pandemic). Border control, quarantine processes, social distancing, personal hygiene, population testing, and contact tracing have all been adopted as global strategies to slow down and eliminate virus transmission (WHO, 2020a). In many countries, social distancing was mandated and strict movement control orders and/or total lockdowns were put in place (Mat et al., 2020).

Nonetheless, at the time of writing this report, more than 6 million COVID-19 cases and 300,000 deaths have been recorded, globally (WHO, 2020b). However, infection rates are declining in some countries (e.g., Malaysia, New Zealand, Taiwan and South Korea) while in others (e.g., the United States, Brazil, India and the United Kingdom) they continue to rise (WHO, 2020b).
It is perhaps surprising, if not alarming, that in many of the latter countries' controls are presently being relaxed. In contrast, the lessons learned in Spain and Italy show how effective tight population controls can be even when there is widespread person-to-person transmission (Saez et al., 2020; Saglietto et al., 2020; WHO, 2020b).

Whatever the case is, the objectives of any mitigation strategies are:

1) to spare the lives of vulnerable people those with diabetes, respiratory problems, compromised immunity or just over 70 years old,

2) to reduce the number of serious cases to a level that health services can cope with, and

3) to eliminate community transmission and later cross border transmission. Some administrations have managed this well, but 
others (notably the UK and US) have not. Indeed, some countries have taken a laissezfaire approach and opted early to have few restrictions in the hope of attaining a "herd immunity". This can be said to have had fairly disastrous consequences, especially in the UK, Sweden and Brazil (Korhonen \& Granberg, 2020; Lancet, 2020; Paital et al., 2020). Even in countries where COVID-19 rates are low, public health officials must remain vigilant to prevent a second wave of infections as was the reported experiences in China and South Korea (Xu \& Li, 2020). These concerns will only increase as crossborder travel begins again.

In this regard, political and diplomatic decisions are especially complex. Opening one's borders to another country has the de facto effect of opening them to all the other countries that one's new partner has (or will develop) mutual travel agreements with.

\section{COVID-19 Infection Parameters and the Call for Personalised Medicine}

New data on several COVID-19 infection parameters are slowly beginning to emerge and should become important resources for COVID-19 researchers. These include relative frequencies of symptomatic versus asymptomatic individuals positive for COVID-19, individual variation in response to re-purposed drug treatments (e.g., chloroquine and hydroxychloroquine), prognostic factors for developing severe COVID-19 (underlying medical conditions and age) and genetic risk factors for COVID-19 susceptibility and severity (Cohen, 2020; Dai, 2020; Gémes et al., 2020; Sanchez-Mazas, 2020; WHO, 2020; Zhao et al., 2020).

From a larger perspective, it is our view that these parameters endorse the call for greater efforts in personalised medicine, especially when specific pharmacological interventions (i.e. vaccines or drugs to COVID-19 and other zoonotic diseases) are yet to be developed. The era of 'one-size-fits-all' medicine seems to be no longer sufficient for disease prevention and treat- ment, as demonstrated in the global struggle to control, diagnose, and treat COVID-19 patients.

In principle, the opportunity now exists for personalised medicine to be more widely adopted with genomic-scale information from patients used for disease screening and treatment, including for prescription of drugs or surgery.

Already a huge body of evidence shows associations between genetic variants in the human genome and susceptibility or resistance towards diseases (Chambers et al., 2016; Hoffmann, 2018; Haydar et al., 2019; Lalrohlui et al., 2020; Nicholls et al., 2020; Sanchez-Mazas, 2020).

Variations in immune gene coding for human leukocyte antigens (HLA), cytokines and killer cell immunoglobulin-like receptors (KIRs) and in many other regions of human genome have now been implicated in serious medical conditions including autoimmune diseases, microbial infections, and cancer development (Edinur et al., 2016; Norhalifah et al., 2018; Saleh et al., 2018; Tao et al., 2020).

For example, $H L A-B * 27$ is associated with the occurrence of ankylosing spondylitis and uveitis, while $H L A-D R B 1^{*} 04$ has been linked to rheumatoid arthritis (Edinur et al., 2013). There are similar findings for other genetic regions where combinatorial interactions between KIR and its HLA ligands may serve to either increase the risk of disease or offer a better prognosis; e.g. KIR2DL1-C2 $2^{+} H L A-C$ in predisposition to preeclampsia and $K I R 2 D L 3-C 1^{+} H L A-C$ in susceptibility to $\mathrm{HCV}$ infection, respectively (Nemat-Gorgani et al., 2014; Tao et al., 2020).

Hence, taken overall many diseases that have now been linked to specific regions in human genome. Advances in molecular technology provide further motivation for a wider application of personalised medicine in our healthcare systems.

In addition, people belonging to particular ethnicities are much more likely to be affected by a characteristic range of diseases. This is because there are differences in frequency distributions of susceptibility markers in people with 
different genetic lineages (Edinur et al., 2012; Bentley et al., 2020).

For example, the native Hawaiians (and possibly their other 350 million Austronesian relatives that are widespread across the wider Asia Pacific region) were reported to have elevated risk from COVID-19. Variants in the APOL1 gene that are associated with kidney diseases are frequently detected in populations with African ancestry (Norhalifah et al., 2016; Bentley et al., 2020; Chambers \& Edinur, 2020; Murray et al., 2020).

Therefore, inclusion of people with different ancestries in this new push for widespread genetic screening will not only avoid disparity in health care services but could also optimize the effectiveness and accuracy of personalised medicine in clinical practice. Attention should equally be given to pharmacogenomics of drug response to make sure that any new drugs and their dosages are fully tailored to best suit people of different genetic backgrounds (Roden \& George Jr., 2002)

Advances in molecular biology including whole genome sequencing or single nucleotide polymorphism chip array technologies provide good platforms for personalised medicine. These latest molecular technologies have the power to quickly gather huge amounts of genomic information at a relatively low cost. Thus, they are perfectly positioned to become a key part in strategic preparedness and response planning for the current COVID-19 outbreak and future pandemics.

It is equally important to note that whole genome sequencing technology was also used to characterize the genome of severe acute respiratory syndrome coronavirus (SARSCoV-2), the virus that was responsible for the massive spread of COVID-19. This took just one week after it was first isolated from clusters of pneumonia patients in Wuhan, China (WHO, 2020b). This effort needs to be maintained as the virus continues to accumulate mutational changes giving rise to new strains (Lokman et al., 2020).

\section{Conclusion}

As COVID-19 continues to spread across the world, its progress has revealed the failure of some social control strategies to effectively contain disease spread and a less than optimal ability to provide treatment for affected individuals, much as recorded for other previous pandemics (LePan, 2020). Personalised medicine can thus become one important new element in an improved pro-active approach. Here, the aim would be to rapidly identify vulnerable individuals and subsequently to design better treatment regimens for them, should COVID-19 or other pandemic appear in future.

The application of genomic technology also will continue to be of importance to gain knowledge about the biology of the virus and will facilitate vaccine development and predict markers of resistance and/or susceptibility. Personalised medicine should thus become a major goal for modern medicine and run in parallel with one of the seventeen Sustainable Development Goals (SDGs) adopted by United Nations to fight against infectious diseases and provide universal health coverage (United Nations, 2019).

\section{Acknowledgements}

We would like to acknowledge the financial support given by the Ministry of Higher Education (Fundamental Research Grant Scheme: FRGS/1/2020/STG03/USM/03/5). Geoffrey K. Chambers thanks Victoria University of Wellington for Alumnus Scholar support.

\section{References}

Bentley, A. R., Callier, S. L., \& Rotimi, C. N. (2020). Evaluating the promise of inclusion of African ancestry populations in genomics. NPJ Genomic Medicine, 5, 5.

Chambers, G. K., Edinur, H. A., \& Dunn, P. P. (2016). New insights into ancestry and health of Polynesians and New Zealand Maori. New Zealand Science Review, 73, 3-10. 
Chambers, G. K., \& Edinur, H.A. (2020). Genetic markers of COVID-19 susceptibility. Journal of Sustainability Science and Management. In-press.

Cohen, M. S. (2020). Hydroxychloroquine for the prevention of Covid-19 - Searching for evidence. The New England Journal of Medicine, 383(6), 585-586.

Dai, X. (2020). ABO blood group predisposes to COVID-19 severity and cardiovascular diseases. European Journal of Preventive Cardiology, 27(13), 1436-1437.

Edinur, H. A., Dunn, P. P. J., Hammond, L., Selwyn, C., Velickovic, Z. M., Lea, R. A., \& Chambers, G. K. (2012). Using HLA loci to inform ancestry and health in Polynesian and Maori populations. Tissue Antigens, 80(6), 509-522.

Edinur, H. A., Dunn, P., Hammond, L., Selwyn, C., Brescia, P., Askar, M., ... Chambers, G. K. (2013). HLA and MICA polymorphism in Polynesians and New Zealand Maori: Implications for ancestry and health. Human Immunology, 74(9), 1119-1129.

Edinur, H. A., Manaf, S. M., \& Mat N. F. C. (2016). Genetic barriers in transplantation medicine. World Journal of Transplantation, 6(3), 532-541.

Gémes, K., Talbäck, M., Modig, K., Ahlbom, A., Berglund, A., Feychting, M., \& Matthews, A. A. (2020). Burden and prevalence of prognostic factors for severe COVID-19 in Sweden. European Journal of Epidemiology, 35(5), 401-409.

Haydar, S., Grigorescu, F., Vintilă, M., Cogne, Y., Lautier, C., Tutuncu, Y., . . . Normand, C. (2019). Fine-scale haplotype mapping of MUT, AACS, SLC6A15 and PRKCA genes indicates association with insulin resistance of metabolic syndrome and relationship with branched chain amino acid metabolism or regulation. PLoS One, 14(3), e0214122.

Hoffmann, M. M. (2018). Towards a more personalized treatment of dyslipidemias to prevent cardiovascular disease. Current Cardiology Reports, 20(7), 56.

Korhonen, J., \& Granberg, B. (2020). Sweden backcasting, now? Strategic planning for Covid-19 mitigation in a Liberal Democracy. Sustainability, 12(10), 4138.

Lalrohlui, F., Zohmingthanga, J., \& Kumar, N. S. (2020). Genomic profiling of mitochondrial DNA reveals novel complex gene mutations in familial type 2 diabetes mellitus individuals from Mizo ethnic population, Northeast India. Mitochondrion, 51, 7-14.

Lancet, T. (2020). COVID-19 in Brazil: "so what?". Lancet, 395(10230), 1110-11.

LePan, N. (2020). Visualizing the history of pandemics. https://www.visualcapitalist. com/ history-of-pandemics-deadliest/.

Lokman, S. M., Rasheduzzaman, M., Salauddin, A., Barua, R., Tanzina, A. Y., Rumi, M. H., .. . Hasan, M. M. (2020). Exploring the genomic and proteomic variations of SARSCoV-2 spike glycoprotein: A computational biology approach. Infection, Genetics and Evolution, 84, 104389.

Mat, N. F. C., Edinur, H. A., Razab, M. K. A. A., \& Safuan, S. (2020). A single mass gathering resulted in massive transmission of COVID-19 infections in Malaysia with further international spread. Journal of Travel Medicine, 27(3), taaa059.

Murray, M. F., Kenny, E. E., Ritchie, M. D., Rader, D. J., Bale, A. E., Giovanni, M. A., \& Abul-Husn, N. S. (2020). COVID-19 outcomes and the human genome. Genetics in Medicine, 22(7), 1175-7.

Nemat-Gorgani, N., Edinur, H. A., Hollenbach, J. A., Traherne, J. A., Dunn, P. P. J., Chambers, G. K., Parham, P., \& Norman, P. J. (2014). KIR diversity in Māori and Polynesians: Populations in which HLA-B is not a significant KIR ligand. Immunogenetics, 66(11), 597-611.

Nicholls, H. L., John, C. R., Watson, D. S., Munroe, P. B., Barnes, M. R., \& Cabrera, C. P. (2020). Reaching the end-game for 
GWAS: machine learning approaches for the prioritization of complex disease loci. Frontiers in Genetics, 11, 350.

Norhalifah, H. K., Mat, N. F. C., \& Edinur, H. A. (2018). Cytokine gene polymorphisms in cancer and inflammatory disorders. Current Immunology Reviews, 14(2), 81-93.

Norhalifah, H. K., Syaza, F. H., Chambers, G. K., \& Edinur, H. A. (2016). The genetic history of Peninsular Malaysia. Gene, 586(1), 129-135.

Paital, B., Das, K., \& Parida, S. K. (2020). Inter nation social lockdown versus medical care against COVID-19, a mild environmental insight with special reference to India. Science of the Total Environment, 728, 138914.

Roden, D. M., \& George Jr, A. L. (2002). The genetic basis of variability in drug responses. Nature Reviews Drug Discovery, 1(1), 37-44.

Saez, M., Tobias, A., Varga, D., \& Barceló, M. A. (2020). Effectiveness of the measures to flatten the epidemic curve of COVID-19. The case of Spain. Science of the Total Environment, 727, 138761.

Saglietto, A., D'Ascenzo, F., Zoccai, G. B., \& De Ferrari, G. M. (2020). COVID-19 in Europe: The Italian lesson. Lancet, 395(10230), 1110-1111.

Saleh, R. M., Zefarina, Z., Mat, N. F. C., Chambers, G. K., \& Edinur, H. A. (2018). Transfusion medicine and molecular genetic methods. International Journal of Preventive Medicine, 9, 45.
Sanchez-Mazas, A. (2020). HLA studies in the context of coronavirus outbreaks. Swiss Medical Weekly, 150(1516).

Tao, S., Kichula K. M., Harrison, G. F., Farias, T. D. J., Palmer, W. H., . . Norman, P. J. (2020). The combinatorial diversity of KIR and HLA class I allotypes in Peninsular Malaysia. Immunology, in press.

United Nations. (2019). Special edition: Progress towards the sustainable development goals. [Report of the Secretary-General]. https:// undocs.org/E/2019/68.

WHO, World Health Organization. (2019). Novel coronavirus (2019- $n \mathrm{CoV})$ : Strategic preparedness and response plan. https:// www.who.int/docs/default-source/ coronaviruse/srp-04022020.pdf.

WHO, World Health Organization. (2020a). COVID-19 strategy update. https://www. who.int/publications/i/item/covid-19strategy-update---14-april-2020.

WHO, World Health Organization. (2020b). Coronavirus disease (COVID-19). Situation Reports 136. https://www.who.int/docs/ default-source/coronaviruse/situationreports/20200604-covid-19-sitrep-136. pdf?sfvrsn=fd36550b 2 .

$\mathrm{Xu}$, S., \& Li, Y. (2020). Beware of the second wave of COVID-19. The Lancet, 395(10233), 1321-1322.

Zhao, J., Yang, Y., Huang, H.-P., Li, D., Gu, D.-F., Lu, X.-F., . . . Liu, Y.-K. (2020). Relationship between the ABO blood group and the COVID-19 susceptibility. medRxiv. 